\title{
Insomnia in the context of traumatic brain injury
}

\author{
Jamie M. Zeitzer, PhD; ${ }^{*}$ Leah Friedman, PhD; Ruth O’Hara, PhD \\ Psychiatry Service, Department of Veterans Affairs Palo Alto Health Care System, Palo Alto, CA; Department of \\ Psychiatry and Behavioral Sciences, Stanford University School of Medicine, Stanford University, Stanford, CA
}

\begin{abstract}
Traumatic brain injury (TBI) is one of the leading causes of morbidity and mortality in the United States. One of the most common comorbidities of TBI is the disruption of normal sleep. While often viewed as a nuisance symptom, sleep disruption can delay TBI recovery and negatively affect many of the psychological (e.g., anxiety, depression) and neuromuscular (e.g., pain) sequelae of TBI, decreasing quality of life. Treatment of sleep disruption in the context of TBI is complicated by issues of an altered neuronal milieu, polypharmacy, and the complex relationship between the various comorbidities often found in patients with TBI. Given the growing number of veterans returning from combat with TBI and the elevated risk of comorbid disrupted sleep, both caused by and independent of TBI, a comprehensive review of sleep disruption and its treatment is of great relevance to the Department of Veterans Affairs.
\end{abstract}

Key words: cognitive behavioral therapy, comorbidity, insomnia, pharmacotherapy, rehabilitation, sleep, sleep disorder, sleep disruption, traumatic brain injury, veterans.

\section{SLEEP DISTURBANCES IN TRAUMATIC BRAIN INJURY: RELEVANCE TO VETERANS}

Sleep disturbances, such as insomnia, are very common following traumatic brain injury (TBI) and have been reported in frequencies up to 84 percent (Table). Sleep disruption can be related to the TBI itself but may also be secondary to neuropsychiatric (e.g., depression, anxiety) or neuromuscular (e.g., pain) conditions associated with TBI or to the pharmacological management of the injury and its consequences (Figure). Sleep distur- bances in TBI may affect or exacerbate psychiatric problems, memory, mood, behavior, and social functioning. Sleep disruption has been shown to hinder overall rehabilitation from TBI and is suggested to have a negative effect on the neural remodeling necessary for recovery from many types of brain injuries [1]. Although increased awareness of the potential negative contribution of sleep disorders to poorer outcome in TBI exists, further studies are necessary to generate additional objective data on these patients in terms of the prevalence, clinical features, types of sleep problems, and relationships between the severity of the TBI and sleep disorders and between sleep disorders and other psychiatric problems, as well as the appropriate treatments for these conditions.

This review focuses on insomnia in the context of TBI. Thus, we will consider insomnia directly caused by TBI (e.g., secondary to neural damage), insomnia indirectly caused by TBI (e.g., secondary to depression), and insomnia unrelated to TBI but occurring in individuals with TBI as being in the context of TBI. In the TBI and sleep literature, these three etiologies are generally not clinically parsed. Insomnia is the most common disorder

\footnotetext{
Abbreviations: $\mathrm{CBT}=$ cognitive-behavioral therapy, CBT-I = CBT for insomnia, EEG = electroencephalography, PTSD = posttraumatic stress disorder, REM = rapid eye movement, $\mathrm{TBI}=$ traumatic brain injury, VA = Department of Veterans Affairs.

* Address all correspondence to Jamie M. Zeitzer, PhD; VA Palo Alto Health Care System, 3801 Miranda Avenue (151Y), Palo Alto, CA 94304; 650-493-5000, ext 62410; fax: 650-852-3297. Email: jzeitzer@stanford.edu DOI:10.1682/JRRD.2008.08.0099
} 
Table.

Survey studies of insomnia in traumatic brain injury (TBI). On average, 40 percent of individuals (1,119 of 2,816) in these studies were reported to have symptoms of insomnia. Methodologies for determination of insomnia in these publications vary widely from surveys to electroencephalography recordings, likely adding to variability in percentage of individuals reported to have insomnia. References are presented in chronological order.

\begin{tabular}{|c|c|c|c|c|}
\hline Reference & $\begin{array}{l}\text { No. Subjects } \\
\text { with TBI }\end{array}$ & $\begin{array}{c}\text { \% with } \\
\text { Disrupted Sleep }\end{array}$ & $\begin{array}{c}\text { TBI Severity } \\
\text { (Physician Rating) }\end{array}$ & $\begin{array}{c}\text { Time Since Injury } \\
\text { (time, range, or mean } \pm \text { SD) }\end{array}$ \\
\hline Rutherford, 1977 [1] & 145 & 15 & Mild, moderate, severe & $6 \mathrm{wk}$ \\
\hline Keshavan et al., 1981 [2] & 60 & 70 & Mild, moderate, severe & $1.5 \mathrm{mo}$ \\
\hline Keshavan et al., 1981 [2] & 60 & 37 & Mild, moderate, severe & $3 \mathrm{mo}$ \\
\hline McLean et al., 1984 [3] & 120 & 36 & Mild, moderate, severe & $1 \mathrm{mo}$ \\
\hline Dikmen et al., 1986 [4] & 19 & 41 & Mild & $1 \mathrm{mo}$ \\
\hline Cohen et al., 1992 [5] & 77 & 52 & Mild, moderate, severe & 24-36 mo \\
\hline $\begin{array}{l}\text { Segalowitz and Lawson, } \\
1995 \text { [6] }\end{array}$ & 346 & 29 & Mild & Unknown \\
\hline Beetar et al., 1996 [7] & 202 & 56 & Mild, moderate, severe & $23.9 \pm 21.2 \mathrm{mo}$ \\
\hline Perlis et al., 1997 [8] & 39 & 53 & Mild & $24.1 \pm 26.8 \mathrm{mo}$ \\
\hline Fichtenberg et al., 2002 [12] & 50 & 30 & Mild, moderate, severe & $4 \mathrm{mo}(0.5-53 \mathrm{mo})$ \\
\hline Mahmood et al., 2004 [13] & 87 & 37 & Mild, moderate, severe & $<1 \mathrm{yr}$ \\
\hline Lundin et al., 2006 [14] & 102 & 21 & Mild & $3 \mathrm{mo}$ \\
\hline Ouellet et al., 2006 [15] & 452 & 29 & Mild, moderate, severe & $7.85 \mathrm{yr}$ \\
\hline Parcell et al., 2006 [16] & 63 & 80 & Mild, moderate, severe & $230 \mathrm{~d}(20-1,194 \mathrm{~d})$ \\
\hline $\begin{array}{l}\text { Worthington and Melia, } \\
2006 \text { [17] }\end{array}$ & 135 & 47 & Mild, moderate, severe & $119.3 \pm 108.8 \mathrm{mo}$ \\
\hline Baumann et al., 2007 [18] & 96 & 3 & Mild, moderate, severe & $6 \mathrm{mo}$ \\
\hline Lew et al., 2007 [19] & 62 & 84 & Mild & Unknown \\
\hline
\end{tabular}

1. Rutherford WH. Sequelae of concussion caused by minor head injuries. Lancet. 1977;1(8001):1-4. [PMID: 63653] DOI:10.1016/S0140-6736(77)91649-X

2. Keshavan MS, Channabasavanna SM, Reddy GN. Post-traumatic psychiatric disturbances: Patterns and predictors of outcome. Br J Psychiatry. 1981;138:157-60. [PMID: 7260498]

DOI:10.1192/bjp.138.2.157

3. McLean A Jr, Dikmen S, Temkin N, Wyler AR, Gale JL. Psychosocial functioning at 1 month after head injury. Neurosurgery. 1984;14(4):393-99. [PMID: 6728140] DOI:10.1097/00006123-198404000-00001

4. Dikmen S, McLean A, Temkin N. Neuropsychological and psychosocial consequences of minor head injury. J Neurol Neurosurg Psychiatry. 1986;49(11):1227-32. [PMID: 3794728$]$

DOI:10.1136/jnnp.49.11.1227

5. Cohen M, Oksenberg A, Snir D, Stern MJ, Groswasser Z. Temporally related changes of sleep complaints in traumatic brain injured patients. J Neurol Neurosurg Psychiatry. 1992;55(4):313-15. [PMID: 1583518]

DOI:10.1136/jnnp.55.4.313

6. Segalowitz SJ, Lawson S. Subtle symptoms associated with self-reported mild head injury. J Learning Disabil. 1995;28(5):309-19. [PMID: 7775851] DOI:10.1177/002221949502800507

7. Beetar JT, Guilmette TJ, Sparadeo FR. Sleep and pain complaints in symptomatic traumatic brain injury and neurologic populations. Arch Phys Med Rehabil. 1996;77(12):1298-1302. [PMID: 8976315]

DOI:10.1016/S0003-9993(96)90196-3

8. Perlis ML, Artiola L, Giles DE. Sleep complaints in chronic postconcussion syndrome. Percept Mot Skills. 1997;84(2):595-99. [PMID: 9106853]

9. Clinchot DM, Bogner J, Mysiw WJ, Fugate L, Corrigan J. Defining sleep disturbance after brain injury. Am J Phys Med Rehabil. 1998;77(4):291-95. [PMID: 9715917] 


\section{Table. (Continued)}

Survey studies of insomnia in traumatic brain injury (TBI). On average, 40 percent of individuals $(1,119$ of 2,816$)$ in these studies were reported to have symptoms of insomnia. Methodologies for determination of insomnia in these publications vary widely from surveys to electroencephalography recordings, likely adding to variability in percentage of individuals reported to have insomnia. References are presented in chronological order.

10. Deb S, Lyons I, Koutzoukis C. Neuropsychiatric sequelae one year after a minor head injury. J Neurol Neurosurg Psychiatry. 1998;65(6):899-902.

[PMID: 9854967]

DOI:10.1136/jnnp.65.6.899

11. Hibbard MR, Uysal S, Sliwinski M, Gordon WA. Undiagnosed health issues in individuals with traumatic brain injury living in the community. J Head Trauma Rehabil. 1998;13(4):47-57. [PMID: 9651239]

DOI:10.1097/00001199-199808000-00005

12. Fichtenberg NL, Zafonte RD, Putnam S, Mann NR, Millard AE. Insomnia in a post-acute brain injury sample. Brain Inj. 2002;16(3):197-206. [PMID: 11874613] DOI:10.1080/02699050110103940

13. Mahmood O, Rapport LJ, Hanks RA, Fichtenberg NL. Neuropsychological performance and sleep disturbance following traumatic brain injury. J Head Trauma Rehabil. 2004;19(5):378-90. [PMID: 15597029] DOI:10.1097/00001199-200409000-00003

14. Lundin A, De Boussard C, Edman G, Borg J. Symptoms and disability until 3 months after mild TBI. Brain Inj. 2006;20(8):799-806. [PMID: 17060147] DOI:10.1080/02699050600744327

15. Ouellet MC, Beaulieu-Bonneau S, Morin CM. Insomnia in patients with traumatic brain injury: Frequency, characteristics, and risk factors. J Head Trauma Rehabil. 2006;21(3):199-212. [PMID: 16717498] DOI:10.1097/00001199-200605000-00001

16. Parcell DL, Ponsford JL, Rajaratnam SM, Redman JR. Self-reported changes to nighttime sleep after traumatic brain injury. Arch Phys Med Rehabil. 2006;87(2):278-85. [PMID: 16442985] DOI:10.1016/j.apmr.2005.10.024

17. Worthington AD, Melia Y. Rehabilitation is compromised by arousal and sleep disorders: Results of a survey of rehabilitation centres. Brain Inj. 2006;20(3):327-32. [PMID: 16537274] DOI:10.1080/02699050500488249

18. Baumann CR, Werth E, Stocker R, Ludwig S, Bassetti CL. Sleep-wake disturbances 6 months after traumatic brain injury: A prospective study. Brain. 2007;130(Pt 7):1873-83. [PMID: 17584779] DOI:10.1093/brain/awm109

19. Lew HL, Poole J, Vanderploeg R, Goodrich GL, Dekelboum S, Guillory SB, Sigford B, Cifu DX. Program development and defining characteristics of returning military in a VA polytrauma network site. J Rehabil Res Dev. 2007;44(7):1027-34. [PMID: 18075959] DOI:10.1682/JRRD.2007.05.0073

20. Schwab KA, Ivins B, Cramer G, Johnson W, Sluss-Tiller M, Kiley K, Lux W, Warden D. Screening for traumatic brain injury in troops returning from deployment in Afghanistan and Iraq: Initial investigation of the usefulness of a short screening tool for traumatic brain injury. J Head Trauma Rehabil. 2007;22(6):377-89. [PMID: 18025970] DOI:10.1097/01.HTR.0000300233.98242.87

21. Bushnik T, Englander J, Wright J. Patterns of fatigue and its correlates over the first 2 years after traumatic brain injury. J Head Trauma Rehabil. 2008;23(1):25-32. [PMID: 18219232]

DOI:10.1097/01.HTR.0000308718.88214.bb

$\mathrm{SD}=$ standard deviation

of sleep in the general population and has even higher prevalence in those who have experienced a TBI [2]. Sleep apnea (i.e., sleep-disordered breathing) is also a prevalent disorder in the general population that leads to disruption of nocturnal sleep and to daytime sleepiness. Given the demographics of veterans, sleep apnea exists commonly in this population [3]. A direct connection between sleep apnea and TBI is unlikely, though sleep apnea will likely compound the difficulties in TBI rehabilitation. Several case studies and reports have also described narcolepsy, another sleep disorder found in $<5$ percent of the general population, in those with TBI [4-6]. These TBI-induced narcolepsy cases are likely due to a disruption of the hypocretin neurotransmitter system localized in the lateral hypothalamus [7]. An extended discussion of narcolepsy, however, is beyond the scope of this review.

\section{INSOMNIA}

Sleep can be characterized by both subjective and objective measures. However, inconsistency between these two measures often characterizes sleep pathology. For example, sleep apnea, present in about half the Department of Veterans Affairs (VA) patient population, can be readily characterized using objective measurements of breathing and electroencephalography (EEG) during an overnight sleep episode [8]. Yet many individuals who, on objective measures, have severely disturbed 


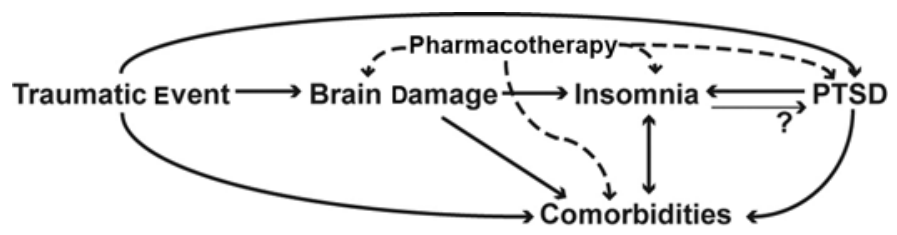

Figure.

Schema of complex relationship between traumatic brain injury, insomnia, and posttraumatic stress disorder (PTSD), as well as associated comorbidities and pharmacotherapy. Single-ended arrows show directional relationships; double-ended arrows show reciprocal relationships. Question mark (“?”) indicates possible, though not proven, causal relationship.

sleep because of sleep apnea often fail to realize that their sleep is disturbed; more often they describe poor daytime alertness. Likewise, many individuals who complain of insomnia have normal sleep when measured by EEG. According to the International Classification of Sleep Disorders, insomnia is defined as a subjective complaint of difficulty initiating or maintaining sleep, waking up too early, or having nonrestorative sleep despite adequate opportunity for sleep [9]. The dichotomy between the complaint of insomnia and a laboratory finding may result from a failure of recording and analytic techniques to accurately describe the physiologic abnormality that underlies this feeling of insomnia. Alternatively, insomnia might be an inherently subjective experience that, in most cases, objective techniques cannot adequately capture. Take, for example, two individuals with, theoretically, identical sleep. One complains of insomnia, the other does not. Because, by definition, insomnia is a subjective complaint, the former individual would be categorized with insomnia and the latter without, despite their "identical” sleep. This frame of reference issue is critical in understanding and interpreting studies of sleep medicine.

Most laboratory studies fail to detect significant differences in the sleep architecture or sleep EEG power spectrum when comparing the sleep of individuals with mild TBI with those without TBI (both with or without the complaint of insomnia). Limited findings indicate possible increased sleep fragmentation (i.e., more transitions between sleep and wakefulness) [10], increased wakefulness during attempted sleep [11], decreased time spent in rapid eye movement (REM) sleep [11], and greater amounts of stage 2 ("lighter") sleep [12]. The inconsistency in specific objective findings may be because of the varied types and causes of TBI under study. In cases of severe TBI, disturbed EEG is often found during both waking hours and sleep. During sleep in those with severe TBI, the EEG during REM sleep is often the most disturbed [11,13-14]. Recovery of normal REM sleep during EEG often parallels and can even precede recovery of general cognitive function [14]. Whether this reflects a common etiology or a beneficial effect of having normal REM sleep is unknown but worthy of future research.

Population-based studies indicate that insomnia occurs in approximately 40 percent of individuals with a TBI of any severity (Table) and is often the most prevalent somatic complaint in this population [15]. We must note, however, that these studies generally relied on survey data and did not adequately control for time since TBI, severity of injury, or the presence of premorbid insomnia. However, we have consistently observed that a greater incidence of subjective insomnia exists in individuals with TBI of any severity than in controls without head trauma. Some studies show, perhaps paradoxically, that those with less severe TBI have higher rates of insomnia than those with more severe TBI [16-18]. This may be because of the underreporting of sleep disturbances in those with severe TBI as these individuals may be unaware of their sleep problems because of impaired memory or cognitive function. Those with mild trauma may be more aware of their sleep issues because of their more acute awareness and sensitivity to post-TBI neurological and neuropsychiatric changes. In general, those with severe TBI report fewer posttraumatic symptoms than those with lesser injuries [19].

A general model of insomnia etiology postulates that two components exist: a general predisposition to developing insomnia and an acute stressor [20]. A TBI can possibly influence both parts of this equation. First, the injury itself could change brain biochemistry or anatomy such that an individual will be more predisposed to develop insomnia. Various neurotransmitters involved in the generation or modulation of sleep and wakefulness have been reported to be disrupted in TBI, including hypocretin-1 [21], dopamine [22], and serotonin [23]. Most of these studies, however, focused on damage secondary to moderate or severe TBI. Little available data exist on the effects of mild TBI on the neurotransmitter systems involved in the generation of sleep and wakefulness. However, even a mild TBI can cause shearing damage to long axons and most of the aforementioned neurotransmitter systems use long axons potentially 
vulnerable to such an insult [24]. We need more data to determine whether mild TBI can cause disruptions in the neurotransmitters critical for sleep and wakefulness. Given the variety of ways in which TBI can occur and the redundancy of sleep- and wakefulness-generating mechanisms, it is quite unlikely that any single biochemical disruption would be responsible for the all of the insomnia observed in those with TBI [25].

TBI can also affect the other part of the insomnia equation because numerous acute stressors commonly associated with a TBI exist that could increase insomnia symptoms. These nonsleep comorbidities include an elevated prevalence of depression (15.6\%-61.0\%) [26], pain (43.1\%) [27], and anxiety (23.0\%) [28]. While direct neural damage resulting from the TBI may cause some of these morbidities, the events surrounding the TBI may cause others. Some could have been premorbid to the TBI or occurred postmorbid to the TBI. The TBI comorbidity with the most notoriety is posttraumatic stress disorder (PTSD), which is characterized by three symptom clusters (reexperiencing, avoidance, hyperarousal) that can all manifest in disrupted sleep. The relative contributions of TBI and PTSD to psychiatric and neuromuscular comorbidities, and likely sleep disruptions such as insomnia, are controversial and not well delineated [2930]. A distinctive aspect of the relationship between sleep disruption and other TBI-related comorbidities is that they frequently reciprocate. For example, depression can lead to insomnia and, conversely, insomnia can initiate or worsen depression [31]. Treatments of comorbidities can also interact. For example, patient use of opioids for daytime pain management can lead to daytime somnolence and disruption of nocturnal sleep. In turn, disturbed nocturnal sleep can lower pain thresholds [32]. Patients must take care with pharmacotherapy so that treatment of one comorbidity minimally disrupts another comorbidity of the TBI (Figure). Unfortunately, no literature specifically addresses the effect of psychiatric comorbidities on the occurrence or severity of insomnia in the context of TBI. Research in this area will be critical to help guide the physician in treating insomnia as a primary or secondary pathology.

\section{Pharmacological Treatment}

The results of only a few clinical studies of pharmacological treatment of sleep disruption in the context of mixed-severity TBI have been published. Li Pi Shan and Ashworth examined zopiclone (nonbenzodiazepine- benzodiazepine receptor agonist) and lorazepam (traditional benzodiazepine) and found them to be equally effective in treating insomnia in TBI [33]. Kemp et al. found that neither melatonin (sleep-promoting hormone) nor amitriptyline (tricyclic antidepressant) was successful in treating insomnia in TBI [34]. Similarly, an administration of sertraline (selective serotonin reuptake inhibitor) found negative results [35]. These studies were small and not well controlled; both positive and negative findings need to be taken with caution. Further, use of medication to treat sleep disruptions associated with TBI generally may not be the most appropriate therapy because concerns often exist about the possibility of interactions with other medications prescribed to these individuals, as well as about the potential side effects of these medications. The benzodiazepines, newer nonbenzodiazepinebenzodiazepine agonists, tricyclic antidepressants, and antihistamines, all of which are commonly used or prescribed to treat sleep disruption, have significant cholinergic side effects that may interfere with neural remodeling and lower seizure threshold. While these side effects may be especially important in individuals with moderate or severe TBI, we must still consider them in individuals with mild TBI. Most pharmacotherapy for sleep is generally recommended for acute, rather than chronic, insomnia [36], and relatively few studies have been published that validate the continuous use of a single pharmacological agent for $>6$ months [37].

Baumann et al. indicated that the wake-promoting neuropeptide hypocretin-1 (orexin A) is abnormally low in the cerebrospinal fluid of individuals in the acute stage post-TBI [21]. Levels of hypocretin-1, however, return to normal within 6 months post-TBI. Thus, future drug development that targets enhancement of the hypocretin system may produce a useful treatment of the daytime sleepiness and nighttime sleep disruption that immediately follow a TBI, but we doubt that it will be useful in treating the long-term sleep disruption that often occurs in the months or years after TBI. Given the wide range of types of neural damage that occurs in the context of TBI, it is unlikely that any single pharmacological treatment, such as enhancement of the hypocretin system, will be appropriate in all circumstances.

\section{Nonpharmacological Treatment}

Although administration of pharmaceuticals is the most widely used treatment of insomnia, meta-analyses derived from studies of patients without TBI have indicated that 
nonpharmacological treatment can be as good, if not better, for the treatment of chronic insomnia [36]. In the population without TBI, various types of nonpharmacological treatments have been tested, including relaxation training, stimulus control, sleep restriction, cognitive therapy, sleep hygiene education, and cognitive-behavioral therapy (CBT) (cognitive therapy plus varying combinations of the previously listed treatments). Relaxation training uses methods such as progressive muscle relaxation for reducing bodily tension or imagery training for curtailing intrusive thoughts to promote good sleep [38]. Stimulus control is based on the concept that following a set of instructions that limits bed use to only sleep or sex will reassociate the bed and bedroom with sleep and reestablish a consistent sleep/waking pattern in the individual [39-42]. Sleep restriction is designed to reduce the amount of nonsleeping excess time a person with insomnia spends in bed to the actual amount of time spent asleep. It thereby creates a mild sleep deprivation that leads to higher quality sleep [43-46]. Cognitive therapy for insomnia focuses on changing maladaptive thinking, which in the context of insomnia focuses on intrusive thoughts often associated with insomnia [47-48]. Cognitive therapy challenges maladaptive and/or inaccurate cognitions about sleep and insomnia [39,49]. Sleep hygiene provides subjects with basic education about daily behaviors (e.g., no evening caffeine), environmental conditions (e.g., sleep in a dark room), and other sleeprelated factors (e.g., regular bed and waking times) that have the potential to interfere with or support good sleep [50-51]. CBT for insomnia (CBT-I) combines cognitive therapy with one or more of the behavioral therapies, such as sleep restriction, sleep hygiene, or stimulus control. Although no standardization of the components of CBT-I exists, the combined approach has well-documented efficacy [36,38,52-60]. A single published report indicates the effectiveness of CBT-I associated with TBI [61]. In this study, individuals with mild to severe TBI and a complaint of insomnia undertook an 8-week course of CBT-I, after which there was a $>10$ percent gain in sleep efficiency. We critically need more studies of nonpharmacological interventions to treat insomnia specifically in mild TBI to establish them as viable alternatives to pharmacotherapy.

\section{CONCLUSIONS}

Both the literature and press have noted the increasing number of veterans diagnosed with mild TBI. Recovery from TBI is often lengthy and difficult and may be hampered by the presence of a comorbid sleep disorder. Primary among these comorbidities is insomnia. Disruption of normal sleep by insomnia can also exacerbate neuropsychiatric and neuromuscular sequelae of TBI that can, in turn, worsen the insomnia. Further complicating treatment is that the drugs commonly used to treat the comorbid psychiatric and neuromuscular problems may also interfere with sleep. Conventional pharmacological treatment of insomnia may also be inappropriate in the context of TBI because of issues of polypharmacy, chronicity of the disorders, and drug dependency. Nonpharmacological treatment, such as CBT-I, has only been recently explained as an alternative and needs further validation. We must understand the interrelationship of common comorbidities such as depression, pain, anxiety, and insomnia to better treat each of these issues. We need more systematic research to provide a foundation for an evidence-based medical approach to the treatment of insomnia in the context of mild TBI.

\section{ACKNOWLEDGMENTS}

\section{Author Contributions:}

Drafting of manuscript: J. M. Zeitzer, L. Friedman. Critical revision of manuscript for important intellectual content: J. M. Zeitzer, L. Friedman, R. O’Hara.

Statistical analysis: J. M. Zeitzer.

Financial Disclosures: The authors have declared that no competing interests exist. No author had any paid consultancy or any other conflict of interest with this article.

Funding/Support: This material was based on work supported by the VA Mental Illness Research, Education, and Clinical Center.

\section{REFERENCES}

1. Worthington AD, Melia Y. Rehabilitation is compromised by arousal and sleep disorders: Results of a survey of rehabilitation centres. Brain Inj. 2006;20(3):327-32.

[PMID: 16537274]

DOI:10.1080/02699050500488249

2. NIH State-of-the-Science Conference statement on manifestations and management of chronic insomnia in adults. NIH Consensus State Sci Statements. 2005;22(2):1-30. [PMID: 17308547] 
3. Sharafkhaneh A, Richardson P, Hirshkowitz M. Sleep apnea in a high risk population: A study of Veterans Health Administration beneficiaries. Sleep Med. 2004;5(4):345-50. [PMID: 15222990]

DOI:10.1016/j.sleep.2004.01.019

4. Francisco GE, Ivanhoe CB. Successful treatment of posttraumatic narcolepsy with methylphenidate: A case report. Am J Phys Med Rehabil. 1996;75(1):63-65.

[PMID: 8645441]

DOI:10.1097/00002060-199601000-00016

5. Castriotta RJ, Wilde MC, Lai JM, Atanasov S, Masel BE, Kuna ST. Prevalence and consequences of sleep disorders in traumatic brain injury. J Clin Sleep Med. 2007;3(4):349-56. [PMID: 17694722]

6. Castriotta RJ, Lai JM. Sleep disorders associated with traumatic brain injury. Arch Phys Med Rehabil. 2001;82(10): 1403-6. [PMID: 11588744] DOI:10.1053/apmr.2001.26081

7. Zeitzer JM, Nishino S, Mignot E. The neurobiology of hypocretins (orexins), narcolepsy and therapeutic interventions. Trends Pharmacol Sci. 2006;27(7):368-74.

[PMID: 16766052]

DOI:10.1016/j.tips.2006.05.006

8. Mustafa M, Erokwu N, Ebose I, Strohl K. Sleep problems and the risk for sleep disorders in an outpatient veteran population. Sleep Breath. 2005;9(2):57-63. [PMID: 15875229] DOI:10.1007/s11325-005-0016-Z

9. American Academy of Sleep Medicine. The international classification of sleep disorders: Diagnostic and coding manual. 2nd ed. Westchester (IL): American Academy of Sleep Medicine; 2005.

10. Prigatano GP, Stahl ML, Orr WC, Zeiner HK. Sleep and dreaming disturbances in closed head injury patients. J Neurol Neurosurg Psychiatry. 1982;45(1):78-80. [PMID: 7062076$]$ DOI:10.1136/jnnp.45.1.78

11. George B, Landau-Ferey J. Twelve months' follow-up by night sleep EEG after recovery from severe head trauma. Neurochirurgia (Stuttg). 1986;29(2):45-47. [PMID: 3713952]

12. Schreiber S, Barkai G, Gur-Hartman T, Peles E, Tov N, Dolberg OT, Pick CG. Long-lasting sleep patterns of adult patients with minor traumatic brain injury (mTBI) and nonmTBI subjects. Sleep Med. 2008;9(5):481-87.

[PMID: 17638592]

DOI:10.1016/j.sleep.2007.04.014

13. Alexandre A, Colombo F, Nertempi P, Benedetti A. Cognitive outcome and early indices of severity of head injury. J Neurosurgery. 1983;59(5):751-61. [PMID: 6619927] DOI:10.3171/jns.1983.59.5.0751

14. Ron S, Algom D, Hary D, Cohen M. Time-related changes in the distribution of sleep stages in brain injured patients. Electroencephalography Clin Neurophysiol. 1980;48(4):
432-41. [PMID: 6153604$]$

DOI:10.1016/0013-4694(80)90135-2

15. Schwab KA, Ivins B, Cramer G, Johnson W, Sluss-Tiller M, Kiley K, Lux W, Warden D. Screening for traumatic brain injury in troops returning from deployment in Afghanistan and Iraq: Initial investigation of the usefulness of a short screening tool for traumatic brain injury. J Head Trauma Rehabil. 2007;22(6):377-89. [PMID: 18025970] DOI:10.1097/01.HTR.0000300233.98242.87

16. Beetar JT, Guilmette TJ, Sparadeo FR. Sleep and pain complaints in symptomatic traumatic brain injury and neurologic populations. Arch Phys Med Rehabil. 1996;77(12): 1298-1302. [PMID: 8976315] DOI:10.1016/S0003-9993(96)90196-3

17. Clinchot DM, Bogner J, Mysiw WJ, Fugate L, Corrigan J. Defining sleep disturbance after brain injury. Am J Phys Med Rehabil. 1998;77(4):291-95. [PMID: 9715917] DOI:10.1097/00002060-199807000-00006

18. Mahmood O, Rapport LJ, Hanks RA, Fichtenberg NL. Neuropsychological performance and sleep disturbance following traumatic brain injury. J Head Trauma Rehabil. 2004;19(5):378-90. [PMID: 15597029] DOI:10.1097/00001199-200409000-00003

19. Trudel TM, Tryon WW, Purdum CM. Awareness of disability and long-term outcome after traumatic brain injury. Rehabil Psychol. 1998;43(4):267-81.

DOI:10.1037/0090-5550.43.4.267

20. Roth T, Drake C. Evolution of insomnia: Current status and future direction. Sleep Med. 2004;5(Suppl 1):S23-30.

[PMID: 15301994]

DOI:10.1016/S1389-9457(04)90004-4

21. Baumann CR, Werth E, Stocker R, Ludwig S, Bassetti CL. Sleep-wake disturbances 6 months after traumatic brain injury: A prospective study. Brain. 2007;130(Pt 7):1873-83. [PMID: 17584779$]$

DOI:10.1093/brain/awm109

22. Donnemiller E, Brenneis C, Wissel J, Scherfler C, Poewe W, Riccabona G, Wenning GK. Impaired dopaminergic neurotransmission in patients with traumatic brain injury: A SPECT study using 123I-beta-CIT and 123I-IBZM. Eur J Nucl Med. 2000;27(9):1410-14. [PMID: 11007526] DOI:10.1007/s002590000308

23. Porta M, Bareggi SR, Collice M, Assael BM, Selenati A, Calderini G, Rossanda M, Morselli PL. Homovanillic acid and 5-hydroxyindole-acetic acid in the csf of patients after a severe head injury. II. Ventricular csf concentrations in acute brain post-traumatic syndromes. Eur Neurol. 1975; 13(6):545-54. [PMID: 1193101] DOI:10.1159/000114710

24. Rutgers DR, Toulgoat F, Cazejust J, Fillard P, Lasjaunias P, Ducreux D. White matter abnormalities in mild traumatic brain injury: A diffusion tensor imaging study. AJNR Am J 
Neuroradiol. 2008;29(3):514-19. [PMID: 18039754$]$ DOI:10.3174/ajnr.A0856

25. España RA, Scammell TE. Sleep neurobiology for the clinician. Sleep. 2004;27(4):811-20. [PMID: 15283019]

26. Kim E, Lauterbach EC, Reeve A, Arciniegas DB, Coburn KL, Mendez MF, Rummans TA, Coffey EC; ANPA Committee on Research. Neuropsychiatric complications of traumatic brain injury: A critical review of the literature (a report by the ANPA Committee on Research). J Neuropsychiatry Clin Neurosci. 2007;19(2):106-27. [PMID: 17431056] DOI:10.1176/appi.neuropsych.19.2.106

27. Nampiaparampil DE. Prevalence of chronic pain after traumatic brain injury: A systematic review. JAMA. 2008; 300(6):711-19. [PMID: 18698069]

DOI:10.1001/jama.300.6.711

28. Moore EL, Terryberry-Spohr L, Hope DA. Mild traumatic brain injury and anxiety sequelae: A review of the literature. Brain Inj. 2006;20(2):117-32. [PMID: 16421060] DOI:10.1080/02699050500443558

29. Lew HL, Vanderploeg RD, Moore DF, Schwab K, Friedman L, Yesavage J, Keane TM, Warden DL, Sigford BJ. Overlap of mild TBI and mental health conditions in returning OIF/OEF service members and veterans. J Rehabil Res Dev. 2008;45(3):xi-xvi. [PMID: 18629743]

30. Hoge CW, McGurk D, Thomas JL, Cox AL, Engel CC, Castro CA. Mild traumatic brain injury in U.S. soldiers returning from Iraq. N Engl J Med. 2008;358(5):453-63. [PMID: 18234750] DOI:10.1056/NEJMoa072972

31. Riemann D. Insomnia and comorbid psychiatric disorders. Sleep Med. 2007;8(Suppl 4):S15-20. DOI:10.1016/S1389-9457(08)70004-2

32. Onen SH, Alloui A, Gross A, Eschallier A, Dubray C. The effects of total sleep deprivation, selective sleep interruption and sleep recovery on pain tolerance thresholds in healthy subjects. J Sleep Res. 2001;10(1):35-42.

[PMID: 11285053] DOI:10.1046/j.1365-2869.2001.00240.x

33. Li Pi Shan RS, Ashworth NL. Comparison of lorazepam and zopiclone for insomnia in patients with stroke and brain injury: A randomized, crossover, double-blinded trial. Am J Phys Med Rehabil. 2004;83(6):421-27. [PMID: 15166685] DOI:10.1097/00002060-200406000-00003

34. Kemp S, Biswas R, Neumann V, Coughlan A. The value of melatonin for sleep disorders occurring post-head injury: A pilot RCT. Brain Inj. 2004;18(9):911-19.

[PMID: 15223743] DOI:10.1080/02699050410001671892

35. Lee H, Kim SW, Kim JM, Shin IS, Yang SJ, Yoon JS. Comparing effects of methylphenidate, sertraline and placebo on neuropsychiatric sequelae in patients with trau- matic brain injury. Human Psychopharmacol. 2005;20(2): 97-104. [PMID: 15641125]

DOI:10.1002/hup.668

36. National Institutes of Health. National Institutes of Health State-of-the-Science Conference Statement on manifestations and management of chronic insomnia in adults, 2005 June 13-15. Sleep. 2005;28(9):1049-57.

[PMID: 16268373]

37. Krystal AD, Erman M, Zammit GK, Soubrane C, Roth T; ZOLONG Study Group. Long-term efficacy and safety of zolpidem extended-release $12.5 \mathrm{mg}$, administered 3 to 7 nights per week for 24 weeks, in patients with chronic primary insomnia: A 6-month, randomized, double-blind, placebocontrolled, parallel-group, multicenter study. Sleep. 2008; 31(1):79-90. [PMID: 18220081]

38. Morin CM, Hauri PJ, Espie CA, Spielman AJ, Buysse DJ, Bootzin RR. Nonpharmacologic treatment of chronic insomnia. An American Academy of Sleep Medicine review. Sleep. 1999;22(8):1134-56. [PMID: 10617176]

39. Espie CA, Lindsay WR, Brooks DN, Hood EM, Turvey T. A controlled comparative investigation of psychological treatments for chronic sleep-onset insomnia. Behav Res Ther. 1989;27(1):79-88. [PMID: 2914008]

DOI:10.1016/0005-7967(89)90123-X

40. Morin CM, Azrin NH. Behavioral and cognitive treatments of geriatric insomnia. J Consult Clin Psychol. 1988;56(5): 748-53. [PMID: 3192792] DOI:10.1037/0022-006X.56.5.748

41. Morin CM, Azrin NH. Stimulus control and imagery training in treating sleep-maintenance insomnia. J Consult Clin Psychol. 1987;55(2):260-62. [PMID: 3571683$]$ DOI:10.1037/0022-006X.55.2.260

42. Riedel B, Lichstein K, Peterson BA, Epperson MT, Means MK, Aguillard RN. A comparison of the efficacy of stimulus control for medicated and nonmedicated insomniacs. Behav Modif. 1998;22(1):3-28. [PMID: 9567734] DOI:10.1177/01454455980221001

43. Friedman L, Benson K, Noda A, Zarcone V, Wicks DA, O’Connell K, Brooks JO 3rd, Bliwise DL, Yesavage JA. An actigraphic comparison of sleep restriction and sleep hygiene treatments for insomnia in older adults. J Geriatr Psychiatry Neurol. 2000;13(1):17-27. [PMID: 10753003] DOI:10.1177/089198870001300103

44. Friedman L, Bliwise DL, Yesavage JA, Salom SR. A preliminary study comparing sleep restriction and relaxation treatments for insomnia in older adults. J Gerontol. 1991; 46(1):P1-8. [PMID: 1986039$]$

45. Hoch CC, Reynolds CF 3rd, Buysse DJ, Monk TH, Nowell P, Begley AE, Hall F, Dew MA. Protecting sleep quality in later life: A pilot study of bed restriction and sleep hygiene. J Gerontol B Psychol Sci Soc Sci. 2001;56(1):52-59. [PMID: 11192338] 
46. Lichstein KL, Riedel BW, Wilson NM, Lester KW, Aguillard RN. Relaxation and sleep compression for late-life insomnia: A placebo-controlled trial. J Consult Clin Psychol. 2001;69(2):227-39. [PMID: 11392600]

DOI:10.1037/0022-006X.69.2.227

47. Fichten CS, Libman E, Creti L, Amsel R, Sabourin S, Brender W, Bailes S. Role of thoughts during nocturnal awake times in the insomnia experience of older adults. Cogn Ther Res. 2001;25(6):665-92. DOI:10.1023/A:1012963121729

48. Wicklow A, Espie CA. Intrusive thoughts and their relationship to actigraphic measurement of sleep: Towards a cognitive model of insomnia. Behav Res Ther. 2000;38(7): 679-93. [PMID: 10875190] DOI:10.1016/S0005-7967(99)00136-9

49. Broomfield NM, Espie CA. Initial insomnia and paradoxical intention: An experimental investigation of putative mechanisms using subjective and actigraphic measurement of sleep. Behav Cogn Psychother. 2003;31:313-24. DOI:10.1017/S1352465803003060

50. Hauri PJ. Sleep hygiene, relaxation therapy, and cognitive interventions. In: Hauri P, editor. Case studies in insomnia. New York (NY): Plenum Medical Book; 1991. p. 65-84.

51. Stepanski EJ, Wyatt JK. Use of sleep hygiene in the treatment of insomnia. Sleep Med Rev. 2003;7(3):215-25.

[PMID: 12927121$]$

DOI:10.1053/smrv.2001.0246

52. Currie SR, Clark S, Hodgins DC, El Guebaly N. Randomized controlled trial of brief cognitive-behavioural interventions for insomnia in recovering alcoholics. Addiction. 2004;99(9): 1121-32. [PMID: 15317632] DOI:10.1111/j.1360-0443.2004.00835.X

53. Currie SR, Wilson KG, Pontefract AJ, DeLaplante L. Cognitive-behavioral treatment of insomnia secondary to chronic pain. J Consult Clin Psychol. 2000;68(3):407-16. [PMID: 10883557] DOI:10.1037/0022-006X.68.3.407

54. Edinger JD, Means MK. Cognitive-behavioral therapy for primary insomnia. Clin Psychol Rev. 2005;25(5):539-58. [PMID: 15951083$]$ DOI:10.1016/j.cpr.2005.04.003
55. Edinger JD, Wohlgemuth WK, Radtke RA, Marsh GR, Quillian RE. Cognitive behavioral therapy for treatment of chronic primary insomnia: A randomized controlled trial. JAMA. 2001;285(14):1856-64. [PMID: 11308399] DOI:10.1001/jama.285.14.1856

56. Espie CA, Inglis SJ, Tessier S, Harvey L. The clinical effectiveness of cognitive behaviour therapy for chronic insomnia: Implementation and evaluation of a sleep clinic in general medical practice. Behav Res Ther. 2001;39(1): 45-60. [PMID: 11125723] DOI:10.1016/S0005-7967(99)00157-6

57. Harvey AG, Tang NK, Browning L. Cognitive approaches to insomnia. Clin Psychol Rev. 2005;25(5):593-611. [PMID: 15979771] DOI:10.1016/j.cpr.2005.04.005

58. Mimeault V, Morin CM. Self-help treatment for insomnia: Bibliotherapy with and without professional guidance. J Consult Clin Psychol. 1999;67(4):511-19.

[PMID: 10450621] DOI:10.1037/0022-006X.67.4.511

59. Morin CM, Bastien C, Guay B, Radouco-Thomas M, Leblanc $J$, Vallières A. Randomized clinical trial of supervised tapering and cognitive behavior therapy to facilitate benzodiazepine discontinuation in older adults with chronic insomnia. Am J Psychiatry. 2004;161(2):332-42.

[PMID: 14754783]

DOI:10.1176/appi.ajp.161.2.332

60. Perlis ML, Smith MT, Orff H, Enright T, Nowakowski S, Jungquist C, Plotkin K. The effects of modafinil and cognitive behavior therapy on sleep continuity in patients with primary insomnia. Sleep. 2004;27(4):715-25.

[PMID: 15283007]

61. Ouellet MC, Morin CM. Efficacy of cognitive-behavioral therapy for insomnia associated with traumatic brain injury: A single-case experimental design. Arch Phys Med Rehabil. 2007;88(12):1581-92. [PMID: 18047872] DOI:10.1016/j.apmr.2007.09.006

Submitted for publication August 11, 2008. Accepted in revised form February 10, 2009. 